\title{
Author Correction: Consolidation of agricultural land can contribute to agricultural sustainability in China
}

Jiakun Duan, Chenchen Ren, Sitong Wang, Xiuming Zhang, Stefan Reis (D), Jianming Xu (D) and Baojing Gu (D)

Correction to: Nature Food https://doi.org/10.1038/s43016-021-00415-5, published online 16 December 2021.

In the version of this article initially published, the first affiliation for Stefan Reis, now reading "UK Centre for Ecology \& Hydrology, Bush Estate, Penicuik, UK" initially appeared, in part, as the "NERC Centre for Ecology \& Hydrology." The change has been made in the HTML and PDF versions of the article.

Published online: 31 January 2022

https://doi.org/10.1038/s43016-022-00469-Z

(C) The Author(s), under exclusive licence to Springer Nature Limited 2022 